\title{
Erratum to: Insulin/glucose infusion successfully resuscitates bupivacaine-induced sudden-onset circulatory collapse in dogs
}

\author{
Mi-Hyun Kim, MD, PhD • Kook-Hyun Lee, MD, PhD • Chong-Soo Kim, MD, PhD • \\ Solmon Yang, MD · Teserendorj Uugangerel, MD · Jong Min Kim, DVM • \\ Byeong-Chul Kang, DVM
}

Published online: 8 August 2013

(C) Canadian Anesthesiologists' Society 2013

\section{Erratum to: Can J Anesth/J Can Anesth (2013)}

\section{0:471-478}

DOI 10.1007/s12630-013-9901-2

In the article entitled: "Insulin/glucose infusion successfully resuscitates bupivacaine-induced suddenonset circulatory collapse in dogs" published in the May 2013 issue, Can J Anesth 2013; 60: 471-8, the name, degree and affiliation of the sixth author is incorrect and should read: Jong Min Kim, DVM, Clinical Research Institute, Seoul National University Hospital, Seoul, South Korea. The publisher apologizes most sincerely for this error.

The online version of the original article can be found under doi:10.1007/s12630-013-9901-2.

M.-H. Kim, MD, PhD

Department of Anesthesiology \& Pain Medicine, Seoul National University Bundang Hospital, Seongnam, South Korea

K.-H. Lee, MD, PhD (ه) · S. Yang, MD · T. Uugangerel, MD Department of Anesthesiology \& Pain Medicine, Seoul National University Hospital, 101 Daehak-Ro Jongno-Gu, Seoul 110-744,

South Korea

e-mail: leekh@snu.ac.kr

C.-S. Kim, MD, PhD

Department of Anesthesiology \& Pain Medicine, Boramae City

Hospital, Seoul, South Korea

J. M. Kim, DVM - B.-C. Kang, DVM

Clinical Research Institute, Seoul National University Hospital,

Seoul, South Korea 